Teodoro J Oscanoa, ${ }^{1,}$, Jose Amado ${ }^{1,2}$, Xavier Vidal $^{3}$, Eamon Laird ${ }^{4}$, Rawia A Ghashut ${ }^{5}$, Roman Romero-Ortuno ${ }^{6,7}$

'Drug Safety Research Center, Facultad de Medicina Humana, Universidad de San Martín de Porres, Hospital Almenara, ESSALUD, Lima, Peru

${ }^{2}$ Facultad de Medicina, Universidad Nacional Mayor de San Marcos, Lima, Peru

${ }^{3}$ Clinical Pharmacology Department, Vall d'Hebron Hospital, Barcelona, Spain

${ }^{4}$ The Irish Longitudinal Study on Ageing, Trinity College Dublin, Ireland

${ }^{5}$ Academic Unit of Anaesthesia, College of Medical, Veterinary and Life of Sciences, University of Glasgow, Glasgow Royal Infirmary, Glasgow, United Kingdom

${ }^{6}$ Discipline of Medical Gerontology, Mercer's Institute for Successful Ageing, St James's Hospital, Dublin, Ireland

${ }^{7}$ Global Brain Health Institute, Trinity College Dublin, Ireland

\title{
The relationship between the severity and mortality of SARS-CoV-2 infection and 25-hydroxyvitamin D concentration a metaanalysis
}

\begin{abstract}
Introduction: There is increasing scientific interest in the possible association between hypovitaminosis D and the risk of SARSCoV-2 infection severity and/or mortality.

Objective: To conduct a metanalysis of the association between 25-hydroxyvitamin D (25(OH)D) concentration and SARS-CoV-2 infection severity or mortality.

Material and methods: We searched PubMed, EMBASE, Google scholar and the Cochrane Database of Systematic Reviews for studies published between December 2019 and December 2020. Effect statistics were pooled using random effects models. The quality of included studies was assessed with the Newcastle-Ottawa Scale (NOS). Targeted outcomes: mortality and severity proportions in COVID-19 patients with 25(OH)D deficiency, defined as serum $25(\mathrm{OH}) \mathrm{D}<50 \mathrm{nmol} / \mathrm{L}$.

Results: In the 23 studies included ( $\mathrm{n}=2692$ ), the mean age was 60.8 (SD \pm 15.9 ) years and $53.8 \%$ were men. Results suggested that vitamin $25(\mathrm{OH}) \mathrm{D}$ deficiency was associated with increased risk of severe SARS-CoV-2 disease (RR 2.00; 95\% Cl 1.47-2.71, 17 studies) and mortality (RR 2.45; 95\% CI 1.24-4.84, 13 studies). Only 7/23 studies reported C-reactive protein values, all of which were $>10 \mathrm{mg} / \mathrm{L}$.

Conclusions 25(OH)D deficiency seems associated with increased SARS-CoV-2 infection severity and mortality. However, findings do not imply causality, and randomized controlled trials are required, and new studies should be designed to determine if decreased $25(\mathrm{OH}) \mathrm{D}$ is an epiphenomenon or consequence of the inflammatory process associated with severe forms of SARSCoV-2. Meanwhile, the concentration of $25(\mathrm{OH}) \mathrm{D}$ could be considered as a negative acute phase reactant and a poor prognosis in COVID-19 infection.
\end{abstract}

Key words: SARS-CoV-2, COVID-19, vitamin D, 25-hydroxyvitamin D, severity

Adv Respir Med. 2021; 89: 145-157

\section{Introduction}

Since the COVID-19 pandemic began in December 2019, and whilst waiting for an effective and safe vaccine, there has been increased urgency to achieve drug therapy with new and old drugs. Among the latter candidates is 25-hydroxyvitamin D (25(OH)D), which has been proposed as a potentially modifiable risk factor for COVID-19 outcomes [1].

Address for correspondence: Teodoro J Oscanoa, Universidad de San Martín de Porres, Facultad de Medicina Humana, Centro de Investigación de Seguridad de Medicamentos, Lima, Peru; e-mail: tjoscanoae@gmail.com

DOI: 10.5603/ARM.a2021.0037

Received: 14.12 .2020

Copyright (C) 2021 PTChP

ISSN 2451-4934 
$25(\mathrm{OH}) \mathrm{D}$ is a steroid hormone, which comes mainly from the synthesis at the level of the skin, of a precursor that is 7-dehydrocholesterol, which due to the action of ultraviolet light (UVL) B (280-315 nm) exposure is converted into vitamin D3 (cholecalciferol). In some countries at far latitudes, this origin is seasonal only [2]. 25(OH) $\mathrm{D}$ can be obtained from diet (e.g., oily fish, eggs, liver) but very few commonly eaten foods contain sufficient amounts, which is why some countries (but only few) have a mandatory vitamin $\mathrm{D}$ food fortification policy [3]. The recommended amount of vitamin D intake in the majority of countries is $10 \mu \mathrm{g}$ or $400 \mathrm{IU}$ of vitamin D daily during winter at least. Vitamin D levels can be affected by obesity, sunscreen, clothing, genetics, gender, smoking and socio-economic status [4]. Vitamin D2 (obtained from dietary intake of mushrooms or some vegetables) and D3 (obtained from sun exposure or diet) are hydroxylated in the liver and kidneys where the active form of this vitamin is generated as, 1,25 Dihydroxycholecalciferol (1,25(OH)2D). Macrophages/dendritic cells and other organ cells also have the ability to convert $25(\mathrm{OH}) \mathrm{D}$ to $1,25(\mathrm{OH}) 2 \mathrm{D}$ via CYP27B1. The biomarker of a patient's VD status is the concentration of total 25(OH)D (25-hydroxyvitamin $\mathrm{D})$ concentration in serum, because vitamin $\mathrm{D}$ deficiency correlates better with $25(\mathrm{OH}) \mathrm{D}$ than with $1,25(\mathrm{OH}) 2 \mathrm{D}$ [5, 6]. The effects of VD on calcium and phosphate absorption, osteoclast activation, and hence on bone calcification and muscle strength are widely known [7]. The VD receptor (VDR) is very widely expressed, including by all leucocyte classes, and it has been demonstrated that many genes are VD responsive [8], including nearly two hundred genes in monocyte/macrophage cells [9]. Other research has shown that cytokine concentrations and proliferation of immune cells can be modulated by VD [10].

Currently, research designs that have been used to postulate a relationship between hypovitaminosis D and the severity of SARS-CoV-2 infection are either ecological, demographic with risk groups for VD deficiency (Mendelian randomization), or studies on the association of $25(\mathrm{OH})$ D levels with the risk of having a positive test for the virus [1]. Ecological studies use databases with information on 25(OH)D concentration of populations and countries and relate it to mortality, recovery, severity or susceptibility to SARS-CoV-2 infection. A published metanalysis that included ecological studies in 51 countries found no correlation between 25(OH)D levels and recovery or mortality rates [11]; however, consid- ering latitude, an inverse relationship was found between mortality and 25(OH)D status in Asia, Middle East and Oceania; and surprisingly, in the USA and South America, the correlation was direct [12-14]. Ilie et al. found that the Pearson correlation coefficients between mean 25(OH)D levels and COVID-19 cases, and mean 25(OH)D levels and COVID-19 deaths per million population were negative and statistically significant based on data from 20 European countries [15]; however, this study was re-analyzed by Kumar et al., adding to the model the life expectancy factor, and the result was the loss of the significance of $25(\mathrm{OH}) \mathrm{D}$ levels as a predictor of mortality from COVID-19 [16].

Mendelian randomization studies use genetic variants as markers to evaluate a causal relationship in observational data [17], and have been used in studies of the association between $25(\mathrm{OH}) \mathrm{D}$ and severity of COVID-19 infection, based on the fact that the polymorphism of the VD receptor has an impact on the response to 25(OH)D. Mendelian randomization studies use the genetic variant as a surrogate variable for 25(OH)D deficiency, to infer the causal effect of an exposure [25(OH)D concentration] to an outcome (COVID-19 susceptibility, severity or mortality) [18]. Currently, 3 studies have been published using Mendelian randomization on the association of 25(OH)D concentration with the risk or severity of COVID-19; one found a relationship [19]which impedes good immune function, is common during winter and spring in regions of high latitude. There is good evidence that vitamin $\mathrm{D}$ deficiency contributes to the seasonal increase of virus infections of the respiratory tract, from the common cold to influenza, and now possibly also COVID-19. This communication explores key factors that make it more likely, particularly in combination, that individuals are vitamin $\mathrm{D}$ deficient. These factors include old age, obesity, dark skin tone and common genetic variants that impede vitamin D status. Precision nutrition is an approach that aims to consider known personal risk factors and health circumstances to provide more effective nutrition guidance in health and disease. In regard to avoiding vitamin $\mathrm{D}$ deficiency, people with excess body fat, a dark skin tone or older age usually need to use a moderately dosed daily vitamin D supplement, particularly those living in a high-latitude region, getting little ultraviolet $\mathrm{B}$ exposure due to air pollution or staying mostly indoors. Carriers of the GC (group-specific component, but the other two did not $[18,20]$. The limitations of this type of study is that it 
uses a surrogate for 25(OH)D deficiency, and in severe cases of COVID-19, it is necessary to have the serum 25(OH)D concentration at the time of hospitalization for COVID-19; on the other hand, the polymorphism with which the individual was born does not predict numerous other factors that could have affected $25(\mathrm{OH}) \mathrm{D}$ status.

The objective of the present study was to perform a systematic review and meta-analytic study on severity or mortality of SARS-CoV-2 infection and 25-hydroxyvitamin D concentration based in observational studies and randomized clinical trials.

\section{Material and methods}

This study was conducted following the guidelines of the Preferred Reporting Items for Systematic Reviews and Meta-analyses (PRISMA) [21].

\section{Search strategy}

Two independent investigators performed a systematic search in PubMed, EMBASE, Google Scholar, preprint servers (medRxiv, bioRxiv and Research Square) and the Cochrane Database of Systematic Reviews for studies published between December 2019 and December, 2020. In addition, we conducted a secondary search based on the references lists of the retrieved articles. The PubMed search strategy is detailed in the Supplementary file.

\section{Eligibility criteria}

We searched for randomized controlled trials (RCTs) or observational studies reporting data on serum 25(OH)D concentration and SARSCoV-2 infection severity or mortality. We included studies in English or other (Russian and Spanish) language (all ages) meeting the following criteria: a) COVID-19 patients were diagnosed according to the interim guidance of the World Health Organization [22]; b) inclusion of the mean and standard deviation for laboratory test values of 25(OH)D, and sample size with demographics, comorbidities, and complications; c) the study presented data on hazard ratios (HRs), relative risks (RRs), or odds ratios (ORs) with confidence intervals (CIs) or offered enough data to allow these to be calculated (including via email correspondence with original authors if necessary); and d) SARS-CoV-2 infection severity criteria were described (generally defined as admission to intensive care unit, acute respiratory distress syndrome and/or need for mechanical ventilation).
The following exclusion criteria were applied: reviews, abstracts, discussion summaries, and insufficient reported data including absence of vitamin $\mathrm{D}$ measurement.

\section{Quality assessment}

The quality of observational studies (cohort and case-control studies) and RCTs were assessed according to the Newcastle-Ottawa Quality Assessment Scale (NOS) [23] and the Cochrane Risk of Bias Assessment Tool [24], respectively. Two investigators evaluated the quality of the studies independently. Conflicting results were resolved by discussion and involvement of a third reviewer if necessary.

\section{Data extraction}

The following data were extracted from each study: authors, study location, year of publication, study design, number of participants, sex, age at baseline, serum VD level, outcome definition, and effect estimates with 95\% confidence intervals (CIs). Targeted outcomes: COVID-19 mortality and/or severity proportions. Even though some studies have considered other 25(OH)D cut-off values [25], in this study we defined Vitamin $\mathrm{D}$ deficiency as serum hydroxyvitamin $\mathrm{D}$ level $<50 \mathrm{nmol} / \mathrm{L}(<20 \mathrm{ng} / \mathrm{mL}$ ) [26]. In a sub-analysis, more severe deficiency was defined as $<30 \mathrm{nmo-}$ $\mathrm{l} / \mathrm{L}(<12 \mathrm{ng} / \mathrm{mL})[27]$.

\section{Statistical analyses}

Primary analyses evaluated the association (HRs, RRs or ORs) between 25-hydroxyvitamin D concentration and SARS-CoV-2 infection severity or mortality. In the metaanalysis, in order to calculate the effect size of $25(\mathrm{OH}) \mathrm{D}$ concentration and gender, the relative risk or odds ratio published by the authors of the included studies were used. We applied random effects with an inverse variance method to calculate the pooled RRs and 95\% CIs according to the heterogeneity between the studies [28]. The overall estimates in the pooled analysis were obtained using Stata 13 software (Stata Corp LP, College Station, TX).

\section{Results}

After screening 745 citations, 23 studies (5 cohort, 11 cases and controls, 7 cross sectional observational studies) were included (Figure 1), combining to a total sample of 2692 participants. The characteristics of the included studies are summarized in Table 1 . The studies were from Belgium [29], China [30, 31], Germany [32], India 


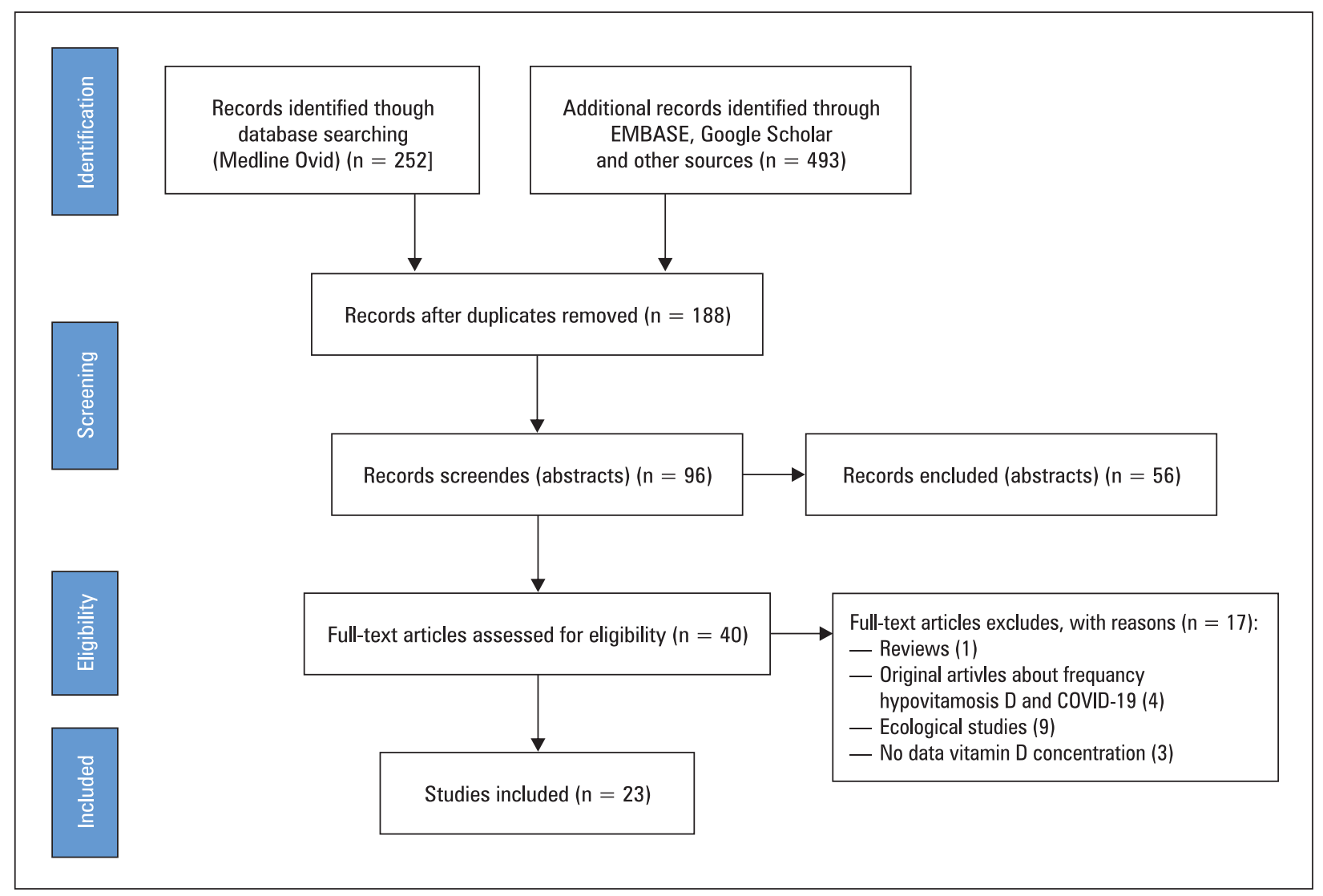

Figure 1. Flowchart of the included studies

[33], Iran [34, 35], Italy [36-38], Philippines [39], Spain [40, 41], Switzerland [42], South Korea [43], Turkey [44, 45], Russia [46], The Netherlands [47], UK $[48,49]$ and USA [50,51]. Overall, mean age was 60.8 (SD 15.9) years and 53.8\% were men. The mean NOS score of the included studies was 8.1 (range: 7-9). The outcomes reported in the included papers are presented in Table 1.

As shown in Figure 2, the metaanalysis suggested that $25(\mathrm{OH}) \mathrm{D}<50 \mathrm{nmol} / \mathrm{L}(<20 \mathrm{ng} / \mathrm{mL})$ was associated with an increased risk of severe disease (RR 2.00; 95\% CI 1.47-2.71, 17 studies) and mortality (RR 2.45; 95\% CI 1.24-4.84, 13 studies). Only $7 / 23$ papers reported C-reactive protein values, all of which were $>10 \mathrm{mg} / \mathrm{L}[31$, $38,41,44,52-54]$.

Subgroup analyses were conducted to assess the effects of age, sex, and the alternative $25(\mathrm{OH})$ D cut-off value $(<30 \mathrm{nmol} / \mathrm{L})$ separately (Table 2$)$. We found that the severity risk seemed higher in people $<60$ years of age $(\mathrm{p}=0.040,4$ studies $)$. The severity risk seemed to increase as the cutoff point for 25-hydroxyvitamin $\mathrm{D}$ concentration decreased ( $\mathrm{p}=0.025,4$ studies). Male sex ( $\mathrm{p}<$ $0.001,7$ studies) also had higher risk of severity and/or mortality.
Two studies analyzed receiver operating characteristic (ROC) curve analyses to find the 25(OH)D cut-off point with the highest sensitivity and specificity for the prediction of severity and/or mortality. Abrishami et al. (2020) found the cut-off point of $<62.5 \mathrm{nmol} / \mathrm{L}(<25 \mathrm{ng} / \mathrm{mL})$ to have a sensitivity of $75 \%$ and a specificity $72 \%$, for differentiating deceased and discharged patients [35]. Ye et al. (2020) observed that a cutoff point of $41.19 \mathrm{nmol} / \mathrm{L}$ had a sensitivity of $87 \%$ and a specificity of $70 \%$ for predicting illness severity [30].

\section{Discussion}

The main finding of the present paper is that according to the included observational studies, 25(OH)D deficiency (serum 25-hydroxyvitamin D concentration $<50 \mathrm{nmol} / \mathrm{L}$ ) was associated with an increased risk of severe disease and mortality from SARS-CoV-2 infection. Our findings do not imply causation because they only summarize the conclusions of observational studies. For example, it is not possible to extrapolate that in acute patients with COVID-19 who have hypovitaminosis $\mathrm{D}$, the immediate replacement of vitamin 


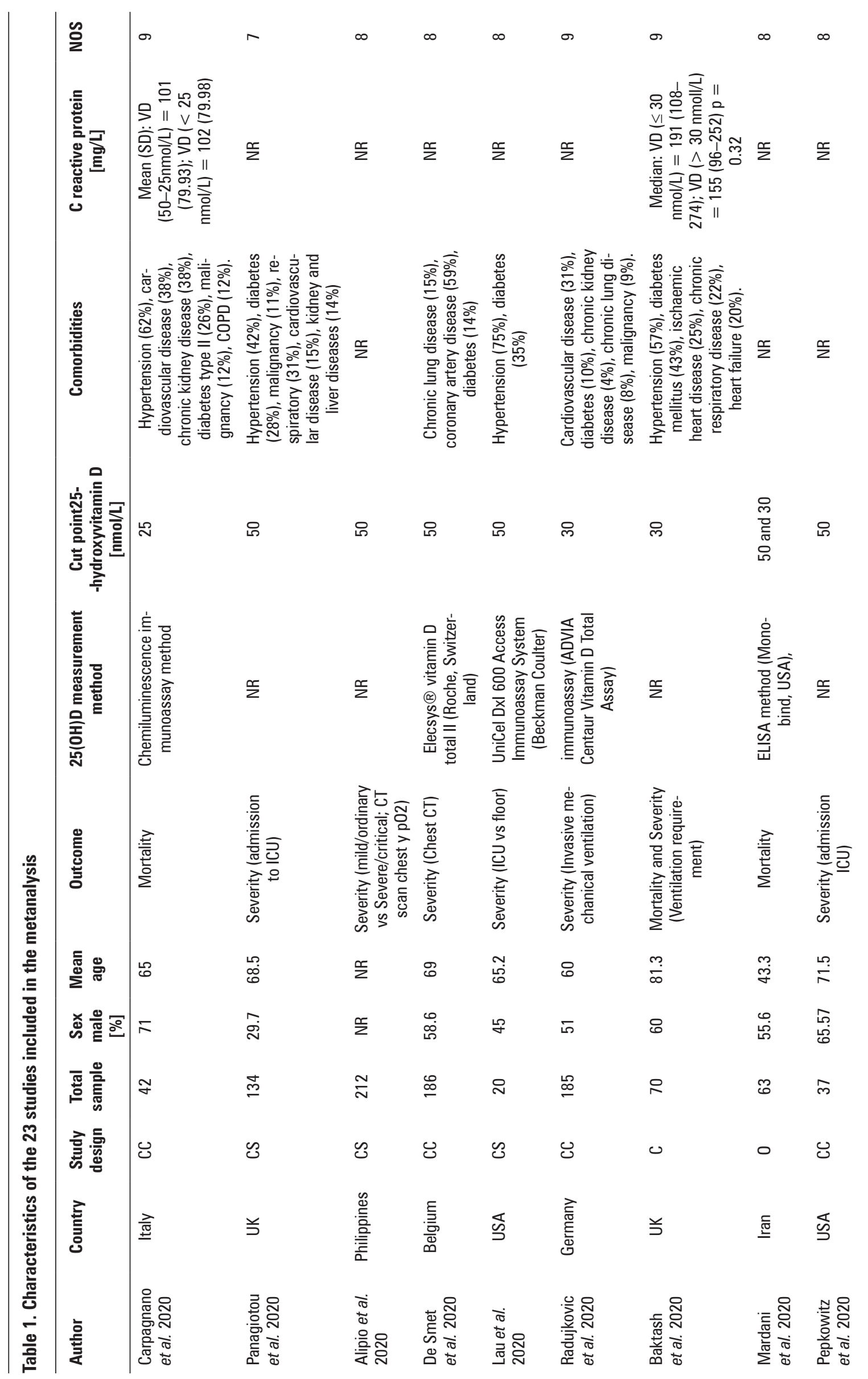




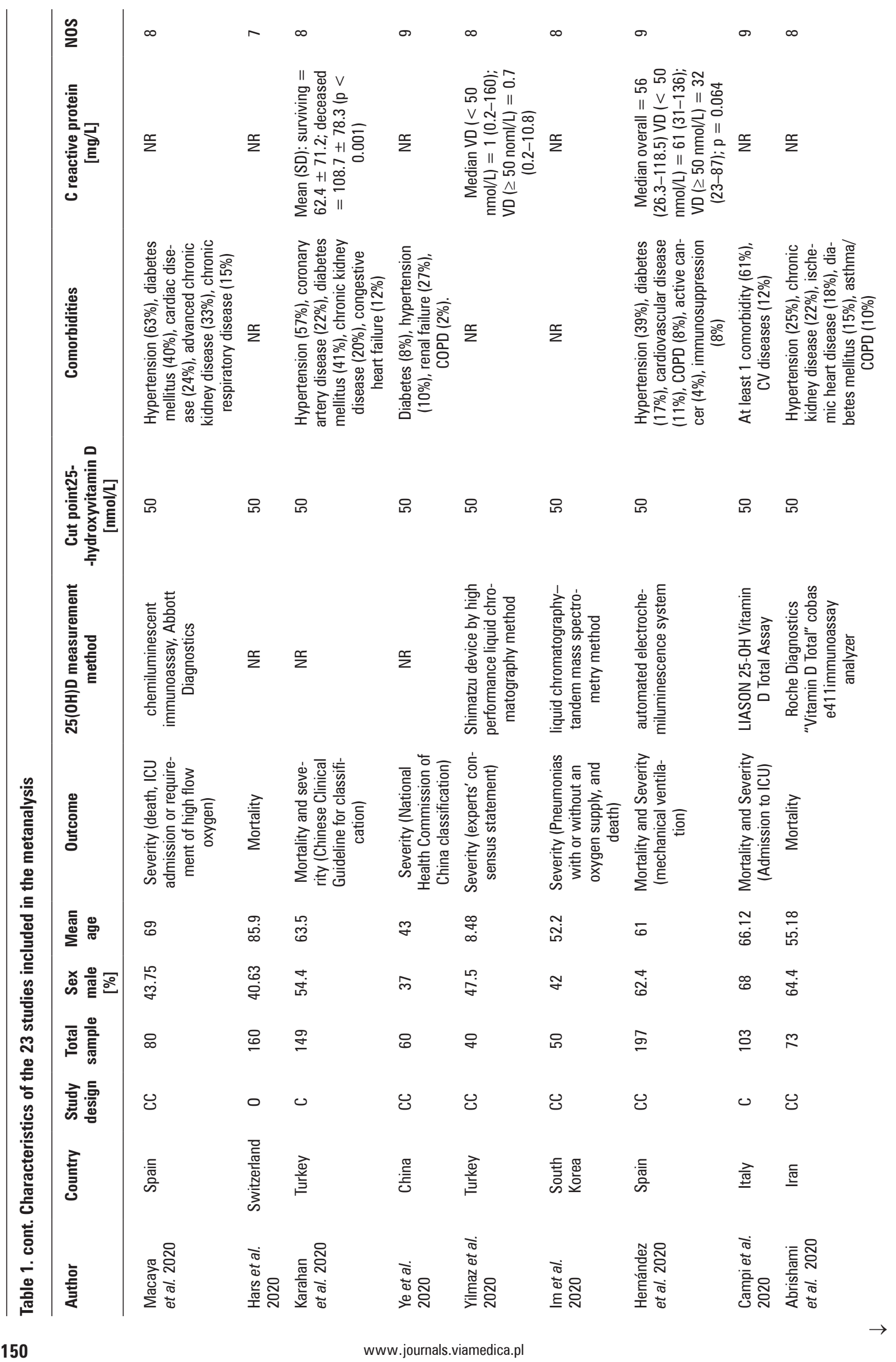




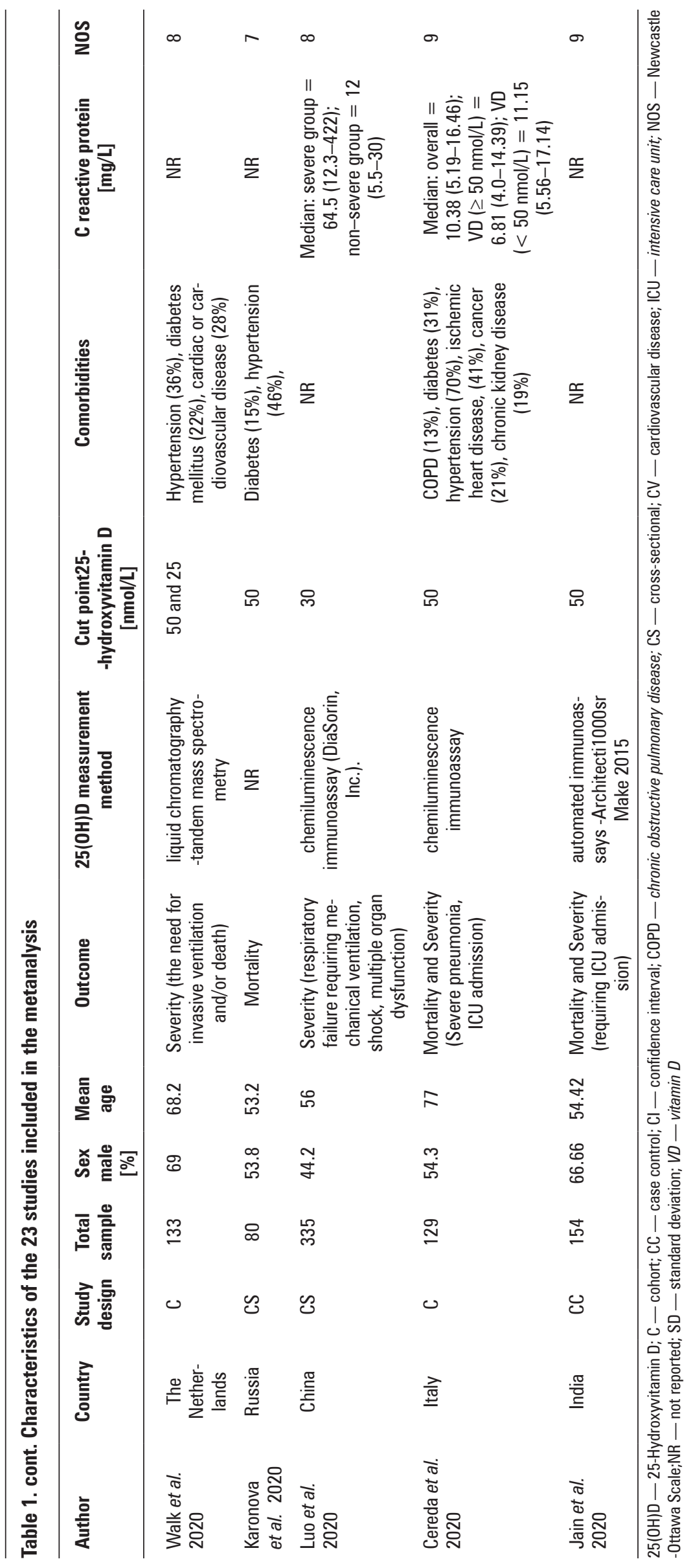


A Study

ID

$\mathrm{RR}(95 \% \mathrm{Cl}) \quad$ Weight

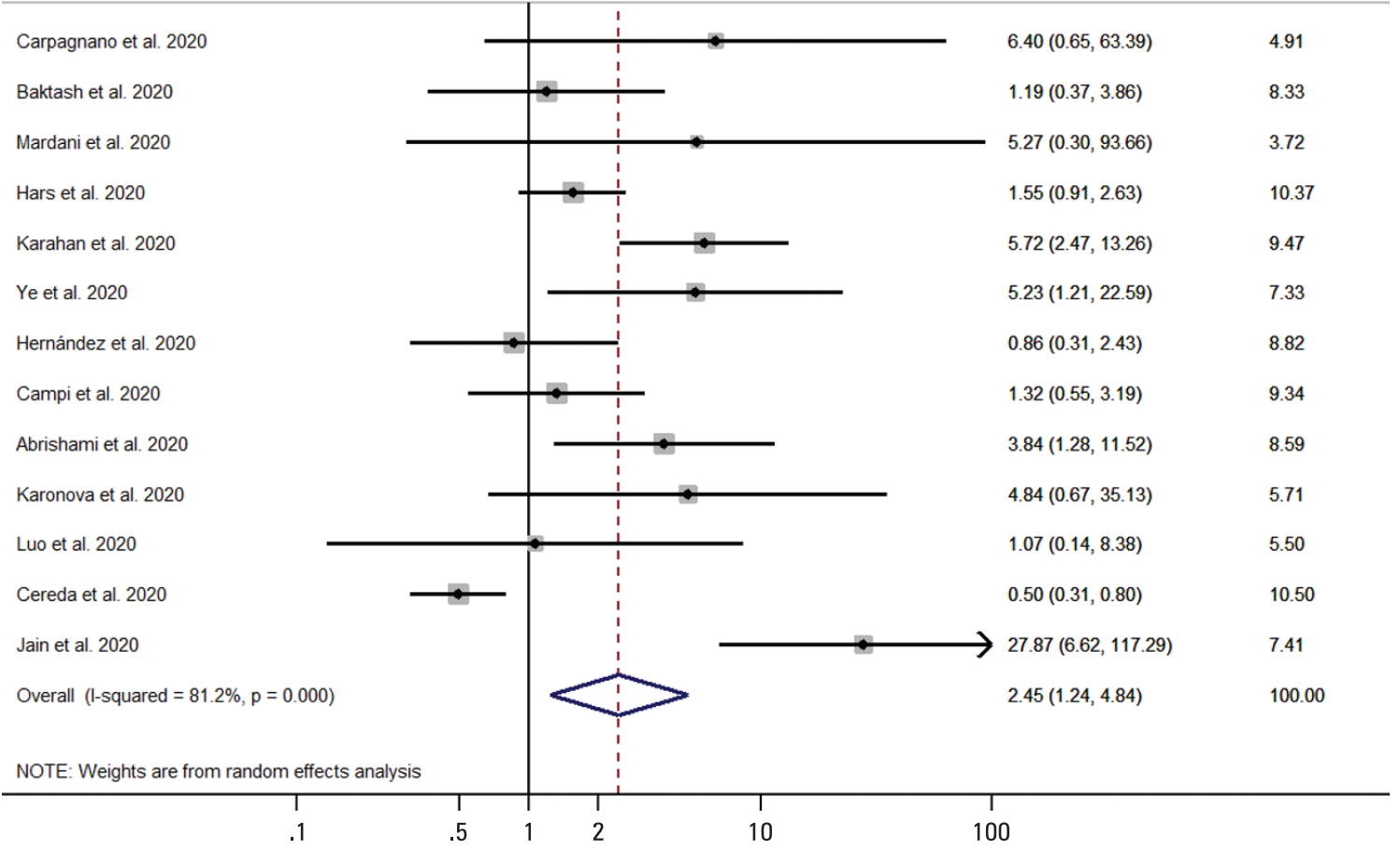

B Study

$\%$

ID

$\mathrm{RR}(95 \% \mathrm{Cl}) \quad$ Weight

\begin{tabular}{llll}
\hline Panagiotou et al. 2020 \\
Alipio et al. 2020 \\
De Smet et al. 2020 \\
Lau et al. 2020 \\
Radujkovic et al. 2020 \\
Baktash et al. 2020 \\
Pepkowitz et al. 2020 \\
Macaya et al. 2020 \\
Karahan et al. 2020 \\
Yilmaz et al. 2020 \\
Im et al. 2020 \\
Hernández et al. 2020 \\
Campi et al. 2020 \\
Walk et al. 2020 \\
Luo et al. 2020 \\
Cereda et al. 2020 \\
Jain et al. 2020 \\
Overall (I-Squared = 83.8\%, $\mathrm{p}=0.000)$ \\
NOTE: Weights are from random effects analysis
\end{tabular}

Figure 2. A. Forest plot of the metaanalysis of the association between mortality from SARS-CoV-2 infection and 25-hydroxyvitamin D concentration ( $<50 \mathrm{nmol} / \mathrm{L}$ ); B. Forest plot of the metaanalysis of the association between severity of SARS-CoV-2 infection and 25-hydroxyvitamin D concentration ( $<50 \mathrm{nmol} / \mathrm{L}$ ). Analysis model: random effects. $\mathrm{Cl}$ - confidence interval; $\mathrm{RR}$ - relative risk 
Table 2. Association between severity of SARS-CoV-2 infection and serum 25-hydroxyvitamin D concentration: summary of subgroup analyses

\begin{tabular}{|c|c|c|c|}
\hline Subgroup & Studies (n) & RR (95\% CI) & $\mathbf{P}$ \\
\hline \multicolumn{4}{|c|}{ Severity } \\
\hline $\begin{array}{l}<30 \\
<50\end{array}$ & $\begin{array}{c}4 \\
14\end{array}$ & $\begin{array}{l}2.45(1.12-5.37) \\
1.79(1.30-2.46)\end{array}$ & $\begin{array}{l}0.025 \\
<0.001\end{array}$ \\
\hline \multicolumn{4}{|l|}{ Mortality } \\
\hline $\begin{array}{l}\text { Cut point } 2 \\
<30 \\
<50\end{array}$ & $\begin{array}{c}4 \\
10\end{array}$ & $\begin{array}{l}1.85(0.79-4.37) \\
2.67(1.20-5.94)\end{array}$ & $\begin{array}{l}0.160 \\
0.016\end{array}$ \\
\hline \multicolumn{4}{|l|}{ Severity } \\
\hline $\begin{array}{l}<60 \\
\geq 60\end{array}$ & $\begin{array}{c}4 \\
12\end{array}$ & $\begin{array}{l}3.05(1.05-8.86) \\
1.83(1.29-2.58)\end{array}$ & $\begin{array}{l}0.040 \\
0.001\end{array}$ \\
\hline \multicolumn{4}{|l|}{ Mortality } \\
\hline $\begin{array}{l}<60 \\
\geq 60\end{array}$ & $\begin{array}{l}6 \\
7\end{array}$ & $\begin{array}{c}5.47(2.31-12.95) \\
1.48(0.71-3.09)\end{array}$ & $\begin{array}{c}<0.001 \\
0.298\end{array}$ \\
\hline \multicolumn{4}{|c|}{ Gender (severity/mortality) } \\
\hline $\begin{array}{l}\text { Male } \\
\text { Female }\end{array}$ & $\begin{array}{l}7 \\
3\end{array}$ & $\begin{array}{l}2.62(1.77-3.87) \\
1.28(0.49-3.32)\end{array}$ & $\begin{array}{c}<0.001 \\
0.613\end{array}$ \\
\hline
\end{tabular}

*One study (Alipio et al. 2020) did not report mean age data

D could improve the prognosis [55]. Another important finding is that there is the possibility that the low concentrations of $25(\mathrm{OH}) \mathrm{D}$ reported are an epiphenomenon of the inflammatory process associated with severe SARS-CoV-2 infection, although only $7 / 23$ studies reported C-reactive protein values, all of which were $>10 \mathrm{mg} / \mathrm{L}$.

We found that the severity risk seemed higher in people younger than 60 years of age; however, this finding related to only 4 studies and had a marginal $\mathrm{P}$ value. Our conclusion that the severity risk seemed to increase as the cut-off point for 25(OH)D concentration decreased adds biological plausibility to the findings. In addition, higher male risk profile, as clinically expected, is given the known epidemiology of COVID-19 infection [56]. It has to be noted that a tradeoff between our two outcomes exists, as very severe cases who died were counted as mortality and not severity for the purpose of association with 25(OH)D status.

The findings of the present study can be compared with similar meta-analytical studies and others published prior to the pandemic, on risk associated with severity of acute respiratory infections. Ghasemian et al. (2020) and Chen et al. (2020) published two meta-analytic studies where they found an association between $25(\mathrm{OH})$ $\mathrm{D}$ deficiency and insufficiency with mortality from SARS-CoV-2 infection; however, ecological studies have the limitation that the reported mortality could have varied in each of the countries, as the pandemic evolved [12, 57]. Another meta-analytic study ( 5 articles included) found a mean 25(OH)D concentration of $18 \mathrm{ng} / \mathrm{mL}$ in severe COVID-19 cases (95\% CI: $1-35$ ) and $26 \mathrm{ng} / \mathrm{mL}$ in non-severe cases (95\% CI: 23.9-28.7) [11]. Pereira et al. (2020) noted that a 25(OH)D concentration of $<50 \mathrm{nmol} / \mathrm{L}$ was associated with an increased risk of hospitalization (3 studies) and mortality from COVID-19 (5 studies) [58]. In a systematic study (7 papers), Munshi et al. (2020) found that patients with poor prognosis had significantly lower serum concentrations of 25(OH)D compared to those with good prognosis, representing an adjusted standardized mean difference of $-5.12(95 \% \mathrm{Cl}=-9.14$ to $-1.10, \mathrm{p}$ $=0.012$ ) [59]. Pham et al. (2020) published in 2019 a meta-analytic study where they found that a $25(\mathrm{OH}) \mathrm{D}$ concentration of $<50 \mathrm{nmol} / \mathrm{L}$ was inversely associated with risk and severity of acute respiratory tract infection [60]. Zhou et al. published a meta-analytical study in 2019 where they documented an increased risk of community-acquired pneumonia in patients with $25(\mathrm{OH})$ $\mathrm{D}$ deficiency $(<50 \mathrm{nmol} / \mathrm{L})$ [61]. Martineau et al. published in 2017 a meta-analytic study with 25 randomized clinical trials, finding that vitamin D supplementation reduced the frequency of acute respiratory infection; however, the benefit was greater in those who were receiving daily or weekly $25(\mathrm{OH}) \mathrm{D}$, and protective effects were 
stronger in those with baseline 25-hydroxyvitamin $\mathrm{D}$ concentrations $<25 \mathrm{nmol} / \mathrm{L}$; and the benefit was not significant in those who received bolus doses [62].

The possible mechanisms that could explain the inverse relationship between the concentration of $25(\mathrm{OH}) \mathrm{D}$ and the frequency of presentation of severe forms of SARS, would be its angiotensin-converting enzyme 2 (ACE2) down-regulation, regulation of IL-6 and prevention of hypocalcemia. Mok et al. in in vitro studies with Vero E6 cells (African green monkey kidney cells) and hNECs (human nasal epithelial cells) found that calcitriol, the active form of vitamin $\mathrm{D}$, has potent activity against SARS-CoV-2; the hypothesis of the possible mechanism of antiviral action would be in the post-entry phase of viral replication [63]. The mechanism of entry into human cells of SARS-CoV-2 is through ACE2, which is part of the renin-angiotensin system (RAS). It has been postulated that $25(\mathrm{OH}) \mathrm{D}$ would have a possible mechanism of protection against acute lung injury (ALI) / acute respiratory distress syndrome (ARDS), through a negative endocrine RAS modulator which inhibits renin expression and generation. This mechanism would be carried out by its inducing action of ACE2 / Ang- (1-7) / MasR axis activity and inhibits renin and the ACE / Ang II / AT1R axis, thereby increasing expression and concentration of ACE2, MasR and Ang-(1-7) [64]. Recently, high levels of ACE have been found in patients with severe COVID-19 with low 25(OH)D concentrations [34]; these findings are compatible with the harmful effect of high levels of ACE in Ang II generation and promote the detrimental effects of the AT1R classical axis (inducing vasoconstriction, inflammation, oxidative stress, and cell proliferation).

Recently, a systematic review found a correlation between premorbid levels of IL-6 and mortality from COVID-19; additionally, the reviewed studies reported concomitant decrease in 25(OH)D concentrations [65]. On the other hand, one of the known actions of concentrations is to modulate the activity of IL-6; therefore, potentially, the control of hypovitaminosis D could reduce the risk of presentation of severe forms of COVID-19 [65]. McGregor et al. (2020) found that CD4 + T cells in the bronchoalveolar lavage fluid (BALF) of patients with COVID-19 are Th1skewed and that VDR is among the top regulators of genes induced by SARS-CoV-2 [66]. Part of the pathophysiology associated with cytokine storm is due to suppression of Th1 cooperative responses, which favors the Th2 type with exces- sive release of tumor necrosis alpha (TNF-alpha) and interleukins. 25(OH)D causes epigenetic re-modelling, induces and recruits a set of TFs (transcription factor), including STAT3 (signal transducer and activator of transcription 3), c-JUN and BACH2 (BTB Domain And CNC Homolog 2) that collectively repress Th1 and Th17 programs and induces IL-10 via IL-6-STAT3 signaling [66]. Recently, a significant increase in inflammation markers (IL-6, TNF $\alpha$ and serum ferritin levels) has been reported in critically ill COVID-19 patients deficient in 25(OH)D ( $<50 \mathrm{nmol} / \mathrm{L})$ [33]. Medical College the current study was undertaken as continuous prospective observational study of 6 weeks. Participants were COVID-19 patients of age group 30-60 years admitted during the study period of 6 weeks. Study included either asymptomatic COVID-19 patients (Group A. Sun et al. (2020) found that $74 \%$ of patients admitted for severe COVID-19 had hypocalcemia and low concentrations of $25(\mathrm{OH}) \mathrm{D}$ and hypoproteinemia, and for these reasons they propose hypocalcemia as a biomarker of clinical severity and prognosis [67]. Actually, the studies on the relationship between the concentration of $25(\mathrm{OH}) \mathrm{D}$ and SARSCoV-2 infection are showing that there is a disturbed parathyroid-vitamin-D axis, which would last up to 8 weeks after the discharge of a patient with SARS-CoV-2 infection with hypovitaminosis D [68]we aimed to investigate associations of VITD status to disease presentation within the CovILD registry. This prospective, multicenter, observational study on long-term sequelae includes patients with COVID-19 after hospitalization or outpatients with persistent symptoms. Eight weeks after PCR confirmed diagnosis, a detailed questionnaire, a clinical examination, and laboratory testing, including VITD status, were evaluated. Furthermore, available laboratory specimens close to hospital admission were used to retrospectively analyze 25 -hydroxyvitamin $\mathrm{D}$ levels at disease onset. A total of 109 patients were included in the analysis (60\% males, $40 \%$ females.

It is important to discuss whether low concentrations of $25(\mathrm{OH}) \mathrm{D}$ in patients with severe COVID-19 infection is a cause or consequence of severe COVID-19 infection, for three main reasons: absence of baseline 25(OH)D measurement before infection, prior knowledge that the concentration of $25(\mathrm{OH}) \mathrm{D}$ decreases as a consequence of an inflammatory process, and most of the studies described on this association did not report the concentration of C-reactive protein (CRP) together with that of 25(OH)D. Before the 
COVID-19 pandemic, it was known that $25(\mathrm{OH})$ $\mathrm{D}$ concentration decreases as a consequence of an inflammatory state, that is, it is considered a negative acute phase reactant [69-71] . Additionally, it has been described that this decrease in $25(\mathrm{OH}) \mathrm{D}$ during these inflammatory processes can persist for up to 3 months [70]. It has been recommended that a reliable clinical interpretation of the 25(OH)D concentration can be made only if the C-reactive protein (CRP) is $<10 \mathrm{mg} / \mathrm{L}$ [71], because it has been described that $25(\mathrm{OH})$ D concentrations are inversely correlated with CRP concentrations [72]. The mechanism involved in the decrease in serum 25(OH)D during an acute inflammatory state would be associated with the decrease in vitamin $\mathrm{D}$ binding protein (VDBP) and increased urinary loss of VDBP that occurs in a systemic inflammatory response (SIR) $[69,70]$. In the present paper, only $7 / 23$ studies reported the concentration of C-reactive protein (CRP), and in all of which it was $>10 \mathrm{mg} / \mathrm{L}$. [31, $38,41,44,52-54]$, therefore, there would be the possibility that one of the causes of the reported decrease in 25(OH)D is an epiphenomenon of the inflammatory process of SARS-CoV-2. Regardless of whether it is its cause or effect, measurement of $25(\mathrm{OH}) \mathrm{D}$ concentration should be considered a marker of inflammation, in addition to markers for inflammation and tissue damage in prognostic models for COVID-19 [29].

The present metaanalysis has its limitations, the main one being that it is based on observational studies and not on interventional studies such as randomized controlled clinical trials. Additionally, the studies used different methodologies to assess 25(OH)D status (e.g. LC-MS/MS, ELISA). It is important to emphasize that no causality can be inferred from our results. However, evidence from observational studies is better than that based on the ecological ones. A limitation is that many studies did not report if the $25(\mathrm{OH})$ D concentration was measured before or during COVID-19 infection, but in the future there may be scope for analyzing vitamin $\mathrm{D}$ in hair to solve this issue [73] the number of requests for vitamin D measurement keeps dramatically increasing year-on-year. Currently, the recognised best marker of vitamin $\mathrm{D}$ status is the concentration of the 25 -hydroxyvitamin $\mathrm{D}(25 \mathrm{OH}$. Indeed, it is important to investigate whether SARS-CoV-2 infection, especially the severe forms, cause a decrease in the concentration of $25(\mathrm{OH}) \mathrm{D}$, in patients who previously had them at normal levels. On the other hand, there is a possible 'healthy user effect' confounder, that is, higher concentrations of 25(OH)D could be seen in people who eat well, have healthy lifestyles and spend more time outdoors exposed to sunlight, which in turn makes them more generally resilient in the face of any acute illness [74]. In other words, 25(OH)D status could be epiphenomenally associated with SARSCoV-2 outcomes.

In conclusion, at present the evidence available supports the hypothesis of increased SARSCoV-2 risk of infection severity and mortality in patients with 25(OH)D deficiency ( $<50 \mathrm{nmol} / \mathrm{L})$. Our findings do not imply causality but support further research in this area, including the conduct of robustly designed randomized controlled trials. On the other hand, new studies should be designed to determine if decreased 25(OH)D is an epiphenomenon or consequence of the inflammatory process associated with severe forms of SARS-CoV-2. Meanwhile, the concentration of $25(\mathrm{OH}) \mathrm{D}$ could be considered as a negative acute phase reactant and a poor prognosis in COVID-19 infection.

\section{Conflict of interest}

None declared.

\section{References:}

1. Manson JE, Bassuk SS. Commentary. Eliminating vitamin D deficiency during the COVID-19 pandemic: A call to action. Metabolism. 2020 [Epub ahead of print]; 112: 154322, doi: 10.1016/j.metabol.2020.154322, indexed in Pubmed: 32712223.

2. Webb AR, Kline L, Holick MF. Influence of season and latitude on the cutaneous synthesis of vitamin D3: exposure to winter sunlight in Boston and Edmonton will not promote vitamin D3 synthesis in human skin. J Clin Endocrinol Metab. 1988; 67(2): 373-378, doi: 10.1210/icem-67-2-373, indexed in Pubmed: 2839537.

3. Buttriss JL, Lanham-New SA. Is a vitamin D fortification strategy needed? Nutr Bull. 2020; 45(2): 115-122, doi: 10.1111/ nbu.12430, indexed in Pubmed: 32536809.

4. Touvier M, Deschasaux M, Montourcy M, et al. Determinants of vitamin D status in Caucasian adults: influence of sun exposure, dietary intake, sociodemographic, lifestyle, anthropometric, and genetic factors. J Invest Dermatol. 2015; 135(2): 378388, doi: 10.1038/iid.2014.400, indexed in Pubmed: 25211176.

5. Rhodes JM, Subramanian S, Laird E, et al. Perspective: vitamin $\mathrm{d}$ deficiency and COVID-19 severity — plausibly linked by latitude, ethnicity, impacts on cytokines, ACE2 and thrombosis. J Intern Med. 2021; 289(1): 97-115, doi: 10.1111/joim.13149, indexed in Pubmed: 32613681

6. Chun RF, Shieh A, Gottlieb C, et al. Vitamin D binding protein and the biological activity of vitamin D. Front Endocrinol (Lausanne). 2019; 10: 718, doi: 10.3389/fendo.2019.00718, indexed in Pubmed: 31708871.

7. Wintermeyer E, Ihle C, Ehnert S, et al. Crucial role of vitamin $\mathrm{D}$ in the musculoskeletal system. Nutrients. 2016; 8(6), doi: 10.3390/nu8060319, indexed in Pubmed: 27258303.

8. Hossein-nezhad A, Spira A, Holick MF. Influence of vitamin D status and vitamin D3 supplementation on genome wide expression of white blood cells: a randomized double-blind clinical trial. PLoS One. 2013; 8(3): e58725, doi: 10.1371/journal.pone.0058725, indexed in Pubmed: 23527013.

9. Nurminen V, Seuter S, Carlberg C, et al. The vitamin D-dependent transcriptome of human monocytes. J Steroid Biochem 
Mol Biol. 2016; 164: 180-187, doi: 10.1016/i.jsbmb.2015.10.018, indexed in Pubmed: 26523676.

10. Wu D, Lewis ED, Pae M, et al. Nutritional modulation of immune function: analysis of evidence, mechanisms, and clinical relevance. Front Immunol. 2018; 9: 3160, doi: 10.3389/ fimmu.2018.03160, indexed in Pubmed: 30697214

11. Ghasemian R, Shamshirian A, Heydari K, et al. The role of vitamin $\mathrm{D}$ in the age of COVID-19: a systematic review and meta-analysis. medRxiv. Preprint availbale online: https://www. medrxiv.org/content/10.1101/ 2020.06.05.20123554v4. [Last accessed at: 12.12.2020].

12. Ghasemian R, Shamshirian A, Heydari K, et al. The role of vitamin D in the age of COVID-19: a systematic review and meta-analysis. , doi: 10.1101/2020.06.05.20123554.

13. Rhodes JM, Subramanian S, Laird E, et al. Editorial: low population mortality from COVID-19 in countries south of latitude 35 degrees North supports vitamin $\mathrm{D}$ as a factor determining severity. Aliment Pharmacol Ther. 2020; 51(12): 1434-1437, doi: 10.1111/apt.15777, indexed in Pubmed: 32311755.

14. Laird E, Rhodes J, Kenny RA. Vitamin D and inflammation: potential implications for severity of COVID-19. Ir Med J. 2020; 113(5): 81, indexed in Pubmed: 32603576.

15. Ilie PC, Stefanescu S, Smith L. The role of vitamin D in the prevention of coronavirus disease 2019 infection and mortality. Aging Clin Exp Res. 2020; 32(7): 1195-1198, doi: 10.1007 s40520-020-01570-8, indexed in Pubmed: 32377965.

16. Srivastava A, Kumar V. Spurious correlation? A review of the relationship between vitamin D and COVID-19 infection and mortality. medRxiv. Preprint available online: https://www. medrxiv.org/content/10.1101/ 2020.05.25.20110338v1. [Last accessed at: 12.12.2020].

17. Burgess S, Davey Smith G, Davies NM, et al. Guidelines for performing Mendelian randomization investigations. Wellcome Open Res. 2019; 4: 186, doi: 10.12688/wellcomeopenres.15555.2, indexed in Pubmed: 32760811.

18. Butler-Laporte G, Nakanishi T, Mooser V, et al. Vitamin D and COVID-19 susceptibility and severity in the COVID-19 host genetics initiative: a mendelian randomization study. medRxiv. Preprint available online: https://www.medrxiv.org/ content/10.1101/ 2020.09.08.20190975v5. [Last accessed at: 12.12.2020].

19. Kohlmeier M. Avoidance of vitamin D deficiency to slow the COVID-19 pandemic. BMJ Nutr Prev Health. 2020; 3(1): 67-73, doi: 10.1136/bminph-2020-000096, indexed in Pubmed: 33230496.

20. Liu Di, Tian Q, Zhang J, et al. Association of 25 hydroxyvitamin D concentration with risk of COVID-19: a Mendelian randomization study. medRxiv. Preprint available online: https:// www.medrxiv.org/content/10.1101/2020.08.09.20171280v2. [Last accessed at: 12.12.2020].

21. Moher D, Liberati A, Tetzlaff J, et al. Preferred reporting items for systematic reviews and meta-analyses: the PRISMA Statement. Open Med. 2009; 3(3): e123-e130, indexed in Pubmed: 21603045 .

22. World Health Organization. Clinical management of severe acute respiratory infection when novel coronavirus (2019$\mathrm{nCoV}$ ) infection is suspected: interim guidance, 28 January 2020. World Health Organization. Available online: https:// apps.who.int/iris/handle/10665/330893. [Last accessed at: 12.12.2020]

23. Stang A. Critical evaluation of the Newcastle-Ottawa scale for the assessment of the quality of nonrandomized studies in meta-analyses. Eur J Epidemiol. 2010; 25(9): 603-605, doi: 10.1007/s10654-010-9491-z, indexed in Pubmed: 20652370.

24. Cumpston M, Li T, Page MJ, et al. Updated guidance for trusted systematic reviews: a new edition of the Cochrane Handbook for Systematic Reviews of Interventions. Cochrane Database Syst Rev. 2019; 10: ED000142, doi: 10.1002/14651858.ED000142, indexed in Pubmed: 31643080.

25. Benskin LL. A basic review of the preliminary evidence that COVID-19 risk and severity is increased in vitamin D deficiency. Front Public Health. 2020; 8: 513, doi: 10.3389/ fpubh.2020.00513, indexed in Pubmed: 33014983.

26. The World Medical Association (WMA) statement on vitamin d insufficiency. October 2015. Retrieved from: https://www. wma.net/policies-post/ wma-statement-on-vitamin-d-insufficiency/. [Last accessed at: 21.11.2020]

27. Boran G, Seheult J. National Laboratory Handbook Laboratory,Testing for Vitamin D Deficiency. 2017. Available online: https://www.hse.ie/eng/ about/who/cspd/ncps/pathology/ /resources/lab-testing-for-vit-d-deficiency11.pdf. [Last accessed at: 21.11.2020].

28. DerSimonian R, Laird N. Meta-analysis in clinical trials. Controlled Clinical Trials. 1986; 7(3): 177-188, doi: 10.1016/01972456(86)90046-2.

29. Smet DDe, Smet KDe, Herroelen P, et al. Vitamin D deficiency as risk factor for severe COVID-19: a convergence of two pandemics. medRxiv. Preprint available online: https://www. medrxiv.org/content/10.1101/2020.05.01.20079376v2. [Last accessed at: 12.12.2020].

30. Ye K, Tang F, Liao X, et al. Does serum vitamin D level affect COVID-19 infection and its severity? A case-control study. J Am Coll Nutr. 2020 [Epub ahead of print]: 1-8, doi: 10.1080/07315724.2020.1826005, indexed in Pubmed: 33048028.

31. Luo X, Liao Q, Shen Y, et al. Vitamin D deficiency is associated with COVID-19 incidence and disease severity in chinese people [corrected]. J Nutr. 2021; 151(1): 98-103, doi: 10.1093/ in/nxaa332, indexed in Pubmed: 33188401.

32. Radujkovic A, Hippchen T, Tiwari-Heckler S, et al. Vitamin D deficiency and outcome of COVID-19 patients. Nutrients. 2020; 12(9), doi: 10.3390/nu12092757, indexed in Pubmed: 32927735.

33. Jain A, Chaurasia R, Sengar NS, et al. Analysis of vitamin D level among asymptomatic and critically ill COVID-19 patients and its correlation with inflammatory markers. Sci Rep. 2020; 10(1): 20191, doi: 10.1038/s41598-020-77093-z, indexed in Pubmed: 33214648.

34. Mardani R, Alamdary A, Mousavi Nasab SD, et al. Association of vitamin $\mathrm{D}$ with the modulation of the disease severity in COVID-19. Virus Res. 2020; 289: 198148, doi: 10.1016/j.virusres.2020.198148, indexed in Pubmed: $\underline{32866536}$.

35. Abrishami A, Dalili N, Mohammadi Torbati P, et al. Possible association of vitamin D status with lung involvement and outcome in patients with COVID-19: a retrospective study. Eur J Nutr. 2020 [Epub ahead of print], doi: 10.1007/s00394-02002411-0, indexed in Pubmed: 33123774.

36. Carpagnano GE, Di Lecce V, Quaranta VN, et al. Vitamin D deficiency as a predictor of poor prognosis in patients with acute respiratory failure due to COVID-19. J Endocrinol Invest. 2021; 44(4): 765-771, doi: 10.1007/s40618-020-01370-x, indexed in Pubmed: 32772324.

37. Campi I, Gennari L, Merlotti D, et al. Vitamin D and COVID-19 severity and related mortality: a prospective study in Italy. SSRN Electronic Journal. , doi: 10.2139/ssrn.3697179.

38. Cereda E, Bogliolo L, Klersy C, et al. Vitamin D $25 \mathrm{OH}$ deficiency in COVID-19 patients admitted to a tertiary referral hospital. Clin Nutr. 2020 [Epub ahead of print], doi: 10.1016/i. clnu.2020.10.055, indexed in Pubmed: 33187772.

39. Alipio M. Vitamin D supplementation could possibly improve clinical outcomes of patients infected with coronavirus 2019 (COVID-2019). SSRN Electronic Journal. 2020, doi: 10.2139/ ssrn.3571484.

40. Macaya F, Espejo Paeres C, Valls A, et al. Interaction between age and vitamin D deficiency in severe COVID-19 infection. Nutr Hosp. 2020; 37(5): 1039-1042, doi: 10.20960/nh.03193, indexed in Pubmed: 32960622.

41. Hernández JL, Nan D, Fernandez-Ayala M, et al. Vitamin D status in hospitalized patients with SARS-CoV-2 infection. J Clin Endocrinol Metab. 2021; 106(3): e1343-e1353, doi: 10.1210/ clinem/dgaa733, indexed in Pubmed: 33159440.

42. Hars M, Mendes A, Serratrice C, et al. Sex-specific association between vitamin D deficiency and COVID-19 mortality in older patients. Osteoporos Int. 2020; 31(12): 2495-2496, doi: 10.1007/s00198-020-05677-6, indexed in Pubmed: 33048168.

43. Im JH, Je YS, Baek J, et al. Nutritional status of patients with COVID-19. Int J Infect Dis. 2020; 100: 390-393, doi: 10.1016/i. iiid.2020.08.018, indexed in Pubmed: 32795605.

44. Karahan S, Katkat F. Impact of serum $25(\mathrm{OH})$ vitamin D level on mortality in patients with COVID-19 in Turkey. J Nutr Health Aging. 2021; 25(2): 189-196, doi: 10.1007/s12603-0201479-0, indexed in Pubmed: 33491033 . 
45. Yılmaz K, Şen V. Is vitamin D deficiency a risk factor for COVID-19 in children? Pediatr Pulmonol. 2020; 55(12): 35953601, doi: 10.1002/ppul.25106, indexed in Pubmed: 33017102.

46. Karonova TL, Andreeva AT, Vashukova MA. Serum 25(oH) D level in patients with CoVID-19. Journal Infectology. 2020; 12(3): 21-27, doi: 10.22625/2072-6732-2020-12-3-21-27.

47. Walk J, Dofferhoff A, Ouweland Jv, et al. Vitamin D - contrary to vitamin $\mathrm{K}$ - does not associate with clinical outcome in hospitalized COVID-19 patients. medRxiv. Preprint available online: https://www.medrxiv.org/content/10.1101/2020.11.07. 20227512v1. [Last accessed at: 12.12.2020].

48. Panagiotou G, Tee SuA, Ihsan Y, et al. Low serum 25-hydroxyvitamin D (25[OH]D) levels in patients hospitalized with COVID-19 are associated with greater disease severity. Clin Endocrinol (Oxf). 2020; 93(4): 508-511, doi: 10.1111/cen.14276, indexed in Pubmed: 32621392.

49. Baktash V, Hosack T, Patel N, et al. Vitamin D status and outcomes for hospitalised older patients with COVID-19. Postgrad Med J. 2020 [Epub ahead of print], doi: 10.1136/postgradmedj-2020-138712, indexed in Pubmed: 32855214.

50. Lau F, Majumder R, Torabi R. Vitamin D insufficiency is prevalent in severe COVID-19. medRxiv. Available online: https://www.medrxiv.org/content/medrxiv/early/2020/04 /28/2020.04.24.20075838.full.pdf. [Last accessed: 12.12.2020].

51. Pepkowitz S, Hobel C, MS J, et al. Vitamin D deficiency is associated with increased COVID-19 severity: prospective screening of at-risk groups is medically indicated. Research Square. Preprint available online: https://assets.researchsquare.com/ files/rs-83262/v1/f5fcf804-21fb-4a03-ade7-fd7d12215419.pdf. [Last accessed: 12.12.2020].

52. Carpagnano GE, Di Lecce V, Quaranta VN, et al. Vitamin D deficiency as a predictor of poor prognosis in patients with acute respiratory failure due to COVID-19. J Endocrinol Invest. 2021; 44(4): 765-771, doi: 10.1007/s40618-020-01370-x, indexed in Pubmed: 32772324.

53. Baktash V, Hosack T, Patel N, et al. Vitamin D status and outcomes for hospitalised older patients with COVID-19. Postgrad Med J. 2020 [Epub ahead of print], doi: 10.1136/postgradmedj-2020-138712, indexed in Pubmed: 32855214.

54. Yılmaz K, Şen V. Is vitamin D deficiency a risk factor for COVID-19 in children? Pediatr Pulmonol. 2020; 55(12): 35953601, doi: 10.1002/ppul.25106, indexed in Pubmed: 33017102.

55. Murai I, Fernandes A, Sales L, et al. Effect of vitamin D3 supplementation vs placebo on hospital length of stay in patients with severe COVID-19: a multicenter, double-blind, randomized controlled trial. , doi: 10.1101/2020.11.16.20232397.

56. Figliozzi S, Masci PG, Ahmadi N, et al. Predictors of adverse prognosis in COVID-19: A systematic review and meta-analysis. Eur J Clin Invest. 2020; 50(10): e13362, doi: 10.1111/ eci.13362, indexed in Pubmed: 32726868.

57. Chen J, Xie L, Yuan P, et al. Low serum vitamin D level and COVID-19 infection and outcomes, a multivariate meta-analysis. , doi: 10.1101/2020.10.24.20218974.

58. Pereira M, Dantas Damascena A, Galvão Azevedo LM, et al. Vitamin D deficiency aggravates COVID-19: systematic review and meta-analysis. Crit Rev Food Sci Nutr. 2020 [Epub ahead of print]: 1-9, doi: 10.1080/10408398.2020.1841090, indexed in Pubmed: 33146028.

59. Munshi R, Hussein MH, Toraih EA, et al. Vitamin D insufficiency as a potential culprit in critical COVID-19 patients. J Med Virol. 2021; 93(2): 733-740, doi: 10.1002/imv.26360, indexed in Pubmed: $\underline{32716073}$.
60. Pham H, Rahman A, Majidi A, et al. Acute respiratory tract infection and 25-hydroxyvitamin d concentration: a systematic review and meta-analysis. Int J Environ Res Public Health. 2019; 16(17), doi: 10.3390/ijerph16173020, indexed in Pubmed: 31438516.

61. Zhou YF, Luo BA, Qin LL. The association between vitamin D deficiency and community-acquired pneumonia: A meta-analysis of observational studies. Medicine (Baltimore). 2019; 98(38): e17252, doi: 10.1097/MD.0000000000017252, indexed in Pubmed: 31567995.

62. Martineau AR, Jolliffe DA, Hooper RL, et al. Vitamin D supplementation to prevent acute respiratory tract infections: systematic review and meta-analysis of individual participant data. BMJ. 2017; 356: i6583, doi: 10.1136/bmj.i6583, indexed in Pubmed: 28202713.

63. Mok C, Ng Y, Ahidjo B, et al. Calcitriol, the active form of vitamin $\mathrm{D}$, is a promising candidate for COVID-19 prophylaxis. , doi: 10.1101/2020.06.21.162396.

64. Malek Mahdavi A. A brief review of interplay between vitamin $\mathrm{D}$ and angiotensin-converting enzyme 2: Implications for a potential treatment for COVID-19. Rev Med Virol. 2020; 30(5): e2119, doi: 10.1002/rmv.2119, indexed in Pubmed: 32584474 .

65. Silberstein M. Correlation between premorbid IL-6 levels and COVID-19 mortality: Potential role for Vitamin D. Int Immunopharmacol. 2020; 88: 106995, doi: 10.1016/j.intimp.2020.106995, indexed in Pubmed: 33182059.

66. McGregor R, Chauss D, Freiwald T, et al. An autocrine Vitamin D-driven Th1 shutdown program can be exploited for COVID-19. bioRxiv. 2020, doi: 10.1101/2020.07.18.210161, indexed in Pubmed: 32743590.

67. Sun JK, Zhang WH, Zou L, et al. Serum calcium as a biomarker of clinical severity and prognosis in patients with coronavirus disease 2019. Aging (Albany NY). 2020; 12(12): 11287-11295, doi: 10.18632/aging.103526, indexed in Pubmed: 32589164.

68. Pizzini A, Aichner M, Sahanic S, et al. Impact of Vitamin D Deficiency on COVID-19-A Prospective Analysis from the CovILD Registry. Nutrients. 2020; 12(9), doi: 10.3390/nu12092775, indexed in Pubmed: 32932831.

69. Haynes BMH, Pfeiffer CM, Sternberg MR, et al. Selected physiologic variables are weakly to moderately associated with 29 biomarkers of diet and nutrition, NHANES 2003-2006. J Nutr. 2013; 143(6): 1001S-10S, doi: 10.3945/in.112.172882, indexed in Pubmed: 23596168.

70. Waldron JL, Ashby HL, Cornes MP, et al. Vitamin D: a negative acute phase reactant. J Clin Pathol. 2013; 66(7): 620-622, doi: 10.1136/iclinpath-2012-201301, indexed in Pubmed: 23454726.

71. Duncan A, Talwar D, McMillan DC, et al. Quantitative data on the magnitude of the systemic inflammatory response and its effect on micronutrient status based on plasma measurements. Am J Clin Nutr. 2012; 95(1): 64-71, doi: 10.3945/ ajcn.111.023812, indexed in Pubmed: 22158726.

72. Ghashut RA, Talwar D, Kinsella J, et al. The effect of the systemic inflammatory response on plasma vitamin $25(\mathrm{OH}) \mathrm{D}$ concentrations adjusted for albumin. PLoS One. 2014; 9(3): e92614, doi: 10.1371/journal.pone.0092614, indexed in Pubmed: 24667823.

73. Zgaga L, Laird E, Healy M. 25-Hydroxyvitamin D measurement in human hair: results from a proof-of-concept study. Nutrients. 2019; 11(2), doi: 10.3390/nu11020423, indexed in Pubmed: 30781610.

74. Bergman P. The link between vitamin D and COVID-19: distinguishing facts from fiction. J Intern Med. 2021; 289(1): 131133, doi: 10.1111/joim.13158, indexed in Pubmed: $\underline{32652766}$. 